\title{
Death-feigning Behavior by Copper-headed Trinket Snakes, Coelognathus radiatus (Boie 1827) (Squamata: Colubridae), in Nepal
}

\author{
Rohit Giri ${ }^{1}$, Roshan Giri ${ }^{2}$, and Kamal Devkota ${ }^{3}$ \\ ${ }^{1}$ Department of Zoology, Prithvi Narayan Campus, Tribhuvan University, Pokhara, Nepal \\ ${ }^{2}$ Shree Chhorepatan Higher Secondary School, Pokhara, Nepal \\ ${ }^{3}$ Nepal Toxinology Association, Kawasoti, Nawalpur, Nepal (devkotakamal67@gmail.com)
}

Photographs by the senior author.

$\mathrm{D}$ eath-feigning (also known as thanatosis or tonic immobility) by snakes is a form of defensive behavior in which a snake acts as if it were dead in response to a predator when threatened or physically touched (e.g., Gregory et al. 2007). Bhattarai et al. (2017) reported this behavior in the Burmese Python (Python bivittatus) from Chitwan National Park, Nepal, the only previous report of death-feigning by a Nepalese snake. Vogel and Yuen (2010) and Nadolski et al. (2020) reported the death-feigning behavior in Copperheaded Trinket Snakes (Coelognathus radiatus) from elsewhere in the species' range.

Copper-headed Trinket Snakes are widely distributed throughout southeastern Asia (e.g., Shah and Tiwari 2004; Whitaker and Captain 2004). When threatened, these snakes may flatten the forebody, assume an S-shaped posture, elevate off the ground, gape, hiss, strike, and feign death (Whitaker and Captain 2004; Vogel and Yuen 2010; Nadolski et al. 2020). Herein, we describe for the first time death-feigning behavior by Copper-headed Trinket Snakes from Nepal.

In 2019 and 2020, during rescue and release operations in Pokhara, Kaski (Fig. 1), we observed three instances of death-feigning by Copper-headed Trinket Snakes. The first episode was at $1240 \mathrm{~h}$ on 10 June 2019 in Siddhartha Rajmarga, (28¹1'34.52"N, 8356'55.76"E; elev. 816 m asl). When released onto the ground, the snake stopped moving, inverted its body, and feigned death with its mouth closed (Fig. 2). After approximately $10 \mathrm{sec}$, it righted itself and began moving slowly while tongue-flicking. Apparently disturbed when we tried to take photographs from a closer distance, it rolled over again and feigned death with its mouth partially open. It repeated similar sequences a total of six times before moving into adjacent natural habitat.

The second case was at about $1100 \mathrm{~h}$ on 22 September 2019 in Khahare, Lakeside (28 $13^{\prime} 16.46^{\prime \prime N}, 83^{\circ} 57^{\prime} 26.16^{\prime \prime E}$;
$808 \mathrm{~m}$ asl). When rescue team members kept their distance, the snake tried to escape but, when handled, the snake feigned death (Fig. 3). After being placed on the ground, the snake maintained thanatosis for about $20 \mathrm{sec}$ before assuming a normal position and attempting to escape. As soon as a team member approached it, it again feigned death after regurgitating a mouse. It continued to feign death while it was bagged.

The third episode (Fig. 4) was at $0743 \mathrm{~h}$ on 4 March 2020 at the Furse Khola Bridge, Chhorepatan $\left(28^{\circ} 11^{\prime} 02.89^{\prime \prime N}\right.$,

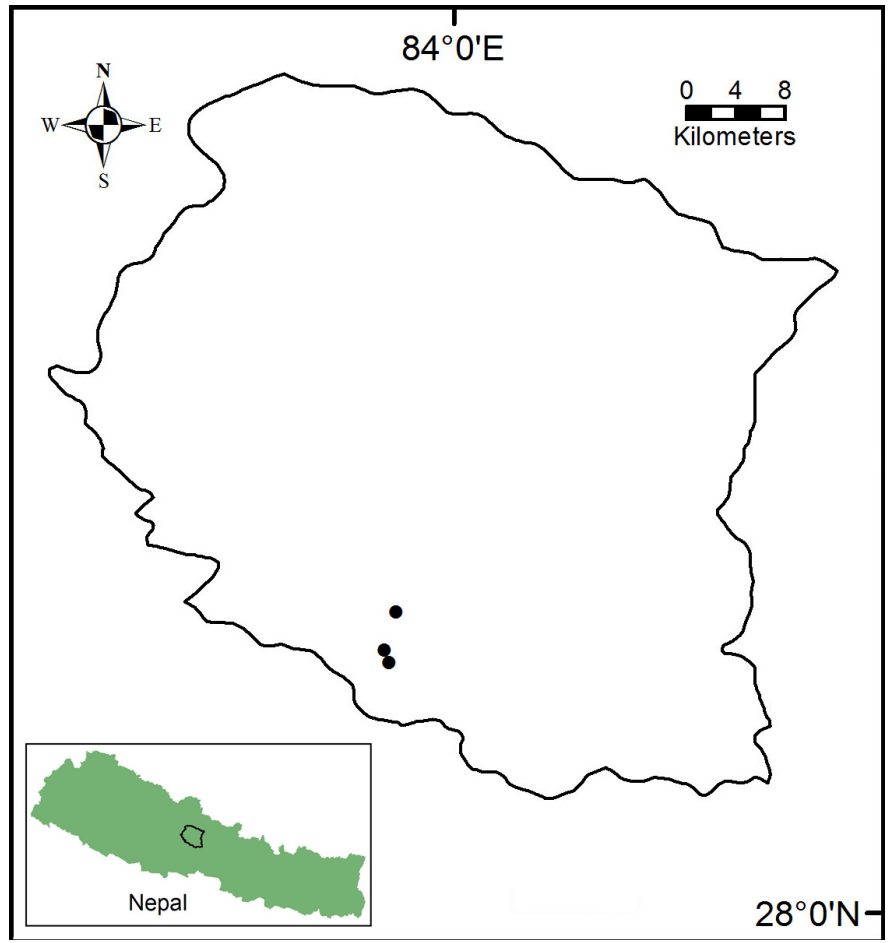

Fig. 1. Map of the Kaski District in Nepal. Dots denote the localities in Pokhara where we observed Copper-headed Trinket Snakes (Coelognathus radiatus) exhibiting death-feigning behavior. 

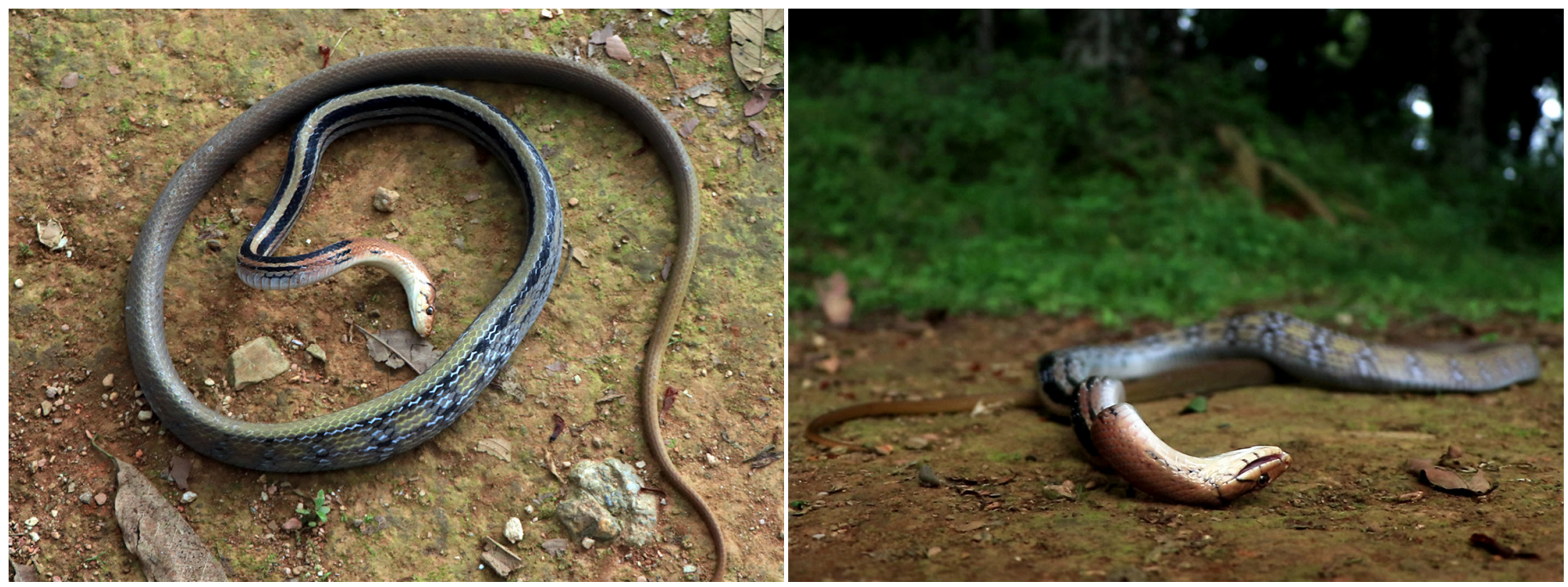

Fig. 2. A Copper-headed Trinket Snake (Coelognathus radiatus) death-feigning with mouth closed (left) and partially open (right).

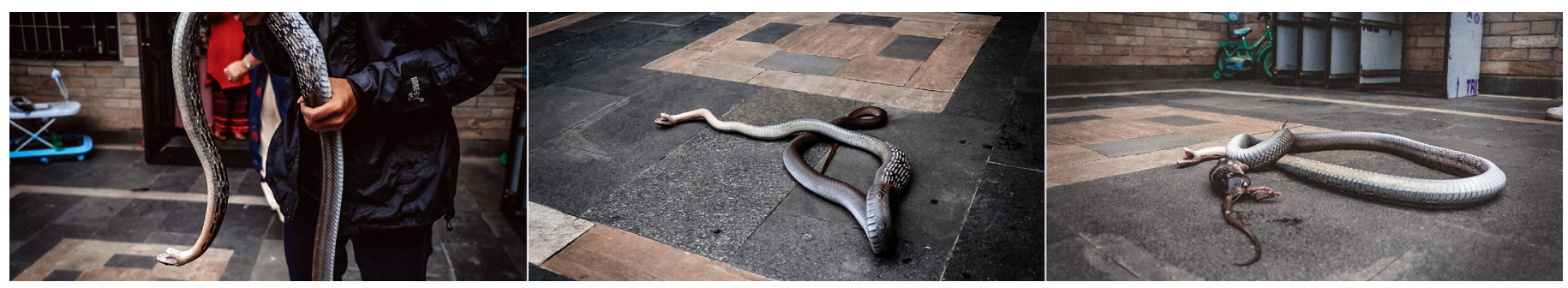

Fig. 3. A Copper-headed Trinket Snake (Coelognathus radiatus) feigning death when handled by a rescue team member (left), when placed on the ground (center), and after regurgitating a mouse (right).

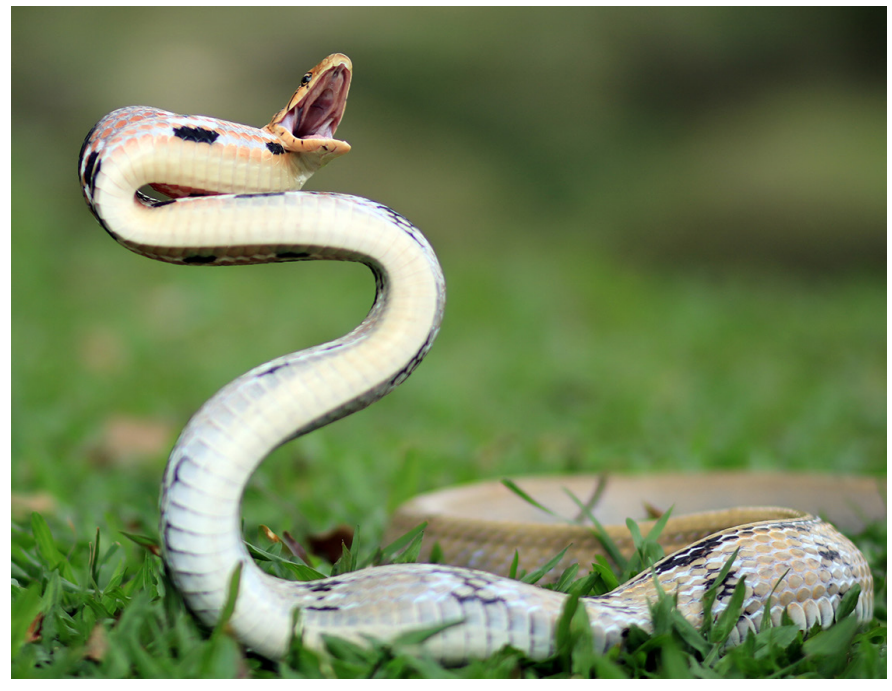

Fig. 4. This Copper-headed Trinket Snake (Coelognathus radiatus) assumed an elevated S-shaped posture and gaped prior to feigning death.

$83^{\circ} 57^{\prime} 7.55^{\prime E} \mathrm{E} ; 47 \mathrm{~m}$ asl). While being released, this snake elevated its head, gaped, and assumed an S-shaped posture (Fig. 4) but subsequently became motionless with the mouth slightly open. Unlike the snakes described previously, this individual feigned death only once.

\section{Acknowledgements}

We thank the rescue team, villagers, and all other helping hands from Pokhara for their cooperation during the rescue and relocation of these snakes. We also thank Hem Bahadur Katuwal for assistance with the map.

\section{Literature Cited}

Bhattarai, S., C.P. Pokheral, and B.R. Lamichhane. 2017. Death feigning behavior in the Burmese Python Python bivittatus Kuhl, 1820 in Chitwan National Park, Nepal. Russian Journal of Herpetology 24: 323-326.

Gregory, P.T., L.A. Isaac, and R.A. Griffiths. 2007. Death-feigning by grass snakes (Natrix natrix) in response to handling by human predators. Journal of Comparative Psychology 121: 123-129.

Nadolski, B., K. Trivedi, K. Ashaharraza, and P. Suwanwaree. 2020. Defensive bahaviors of Copper-headed Trinket Snakes, Coelognathus radiatus (Boie 1827) (Squamata: Colubridae), from the Sakaerat Biosphere Reserve, Thailand. Reptiles \& Amphibians 26: 243-244.

Shah, K.B. and S. Tiwari. 2004. Herpetofauna of Nepal: A Conservation Companion. IUCN Nepal, Patan, Nepal.

Vogel, G. and H.K.H. Yuen. 2010. Death feigning behavior in three colubrid species of tropical Asia. Russian Journal of Herpetology 17: 15-21.

Whitaker, R. and Captain, A. 2004. Snakes of India. The Field Guide. Draco Books, Chennai, India. 